OPEN ACCESS

Edited by:

Christian Chabannon,

Aix-Marseille University, France

Reviewed by:

Joerg Halter,

University of Basel, Switzerland

Sergio Querol,

Banc de Sang i Teixits, Spain

*Correspondence:

Katrine Kielsen

katrinekielsen@dadlnet.dk

Specialty section:

This article was submitted to Alloimmunity and Transplantation,

a section of the journal

Frontiers in Immunology

Received: 27 October 2017

Accepted: 15 January 2018

Published: 02 February 2018

Citation:

Kielsen K, Enevold C, Heilmann C, Sengeløv $H$, Pedersen $A E$, Ryder $L P$ and Müller K (2018) Donor Genotype in the Interleukin-7 Receptor $\alpha$-Chain

Predicts Risk of Graft-versus-Host

Disease and Cytomegalovirus

Infection after Allogeneic

Hematopoietic Stem Cell

Transplantation.

Front. Immunol. 9:109.

doi: 10.3389/fimmu.2018.00109

\section{Donor Genotype in the Interleukin-7 Receptor $\alpha$-Chain Predicts Risk of Graft-versus-Host Disease and Cytomegalovirus Infection after Allogeneic Hematopoietic Stem Cell Transplantation}

\author{
Katrine Kielsen ${ }^{1,2 *}$, Christian Enevold ${ }^{1}$, Carsten Heilmann ${ }^{2}$, Henrik Sengeløv ${ }^{3}$, \\ Anders Elm Pedersen ${ }^{4,5}$, Lars P. Ryder ${ }^{6}$ and Klaus Müller ${ }^{1,2}$
}

${ }^{1}$ Institute for Inflammation Research, Department of Rheumatology and Spine Disease, Copenhagen University Hospital Rigshospitalet, Copenhagen, Denmark, ${ }^{2}$ Haematopoietic Stem Cell Transplantation and Primary Immune Deficiency, Department of Pediatrics and Adolescent Medicine, Copenhagen University Hospital Rigshospitalet, Copenhagen, Denmark, ${ }^{3}$ Department of Hematology, Copenhagen University Hospital Rigshospitalet, Copenhagen, Denmark, ${ }^{4}$ Department of Immunology and Microbiology, University of Copenhagen, Copenhagen, Denmark, ${ }^{5}$ Department of Odontology, University of Copenhagen, Copenhagen, Denmark, ${ }^{6}$ The Tissue Typing Laboratory, Department of Clinical Immunology, Copenhagen University Hospital Rigshospitalet, Copenhagen, Denmark

The efficacy of allogeneic hematopoietic stem cell transplantation (HSCT) is challenged by acute and chronic graft-versus-host disease (aGVHD and cGVHD) and viral infections due to long-lasting immunodeficiency. Interleukin-7 (IL-7) is a cytokine essential for de novo $\mathrm{T}$ cell generation in thymus and peripheral T cell homeostasis. In this study, we investigated the impact of the single nucleotide polymorphism rs6897932 in the IL-7 receptor $\alpha$-chain (IL-7R $\alpha$ ) which has previously been associated with several autoimmune diseases. We included 460 patients undergoing allogeneic HSCT after a myeloablative conditioning. Patients had a median age of 26.3 years (0.3-67.0 years), and $372(80.9 \%)$ underwent HSCT for malignant diseases. Donors were matched sibling donors $(n=147)$, matched unrelated donors $(n=244)$ or mismatched unrelated donors $(n=69)$, and the stem cell source were either bone marrow $(n=329)$ or peripheral blood ( $n=131)$. DNA from donors was genotyped for the IL-7R $\alpha$ single nucleotide polymorphism (SNP) rs6897932 using an allele-specific primer extension assay (CC: $n=252$, CT: $n=178, T \mathrm{~T}: n=30$ ). The donor T allele was associated with a higher risk of grades III-IV aGVHD $(\mathrm{HR}=2.0,95 \% \mathrm{Cl}=1.1-3.8, P=0.034)$ and with significantly increased risk of extensive cGVHD $(H R=2.0,95 \% \mathrm{Cl}=1.1-3.6, P=0.025)$ after adjustment for potential risk factors. In addition, the $\Pi$ genotype was associated with a higher risk of cytomegalovirus (CMV) infection post-transplant ( $H R=2.4,95 \%$ $\mathrm{Cl}=1.2-4.3, P=0.0068$ ). Numbers of $\mathrm{T}$ cells were significantly higher on day +60 in patients receiving a rs6897932 $\Pi$ graft (CD3+: 109\% increase, $P=0.0096$; CD4+:

Abbreviations: HSCT, hematopoietic stem cell transplantation; GVHD, graft-versus-host disease; IL-7R $\alpha$, interleukin-7 receptor $\alpha$-chain; TBI, total body irradiation; ATG, anti-thymocyte globulin; CMV, cytomegalovirus; EBV, Epstein-Barr virus. 
64\% increase, $P=0.038$; CD8+: $133 \%$ increase, $P=0.011$ ). Donor heterozygosity for the $T$ allele was associated with inferior overall survival $(H R=1.7,95 \% \mathrm{Cl}=1.2-2.3$, $P=0.0027)$ and increased treatment-related mortality $(\mathrm{HR}=2.3,95 \% \mathrm{Cl}=1.3-4.0$, $P=0.0047)$, but was not associated with the risk of relapse $(P=0.35)$. In conclusion, the IL-7R $\alpha$ rs6897932 genotype of the donor is predictive of aGVHD and cGVHD, CMV infection, and mortality following HSCT. These findings indicate that IL-7R $\alpha$ SNP typing of donors may optimize donor selection and facilitate individualization of treatment in order to limit treatment-related complications.

Keywords: interleukin-7 receptor, single nucleotide polymorphisms, allogeneic hematopoietic stem cell transplantation, graft-versus-host disease, $\mathrm{T}$ cell reconstitution, cytomegalovirus infection

\section{INTRODUCTION}

Allogeneic hematopoietic stem cell transplantation (HSCT) is a treatment of high-risk leukemia and a number of benign hematological disorders. In the treatment of leukemia, the outcome of HSCT is based on an immune-mediated cytotoxic attack on the malignant cells and persisting immune surveillance, also known as the graft-versus-leukemia effect. However, the success of HSCT is limited by long-lasting T cell dysfunction with risk of severe infections and development of graft-versus-host disease (GVHD), both contributing significantly to non-relapse mortality (1-3). More detailed insight into the mechanisms of $\mathrm{T}$ cell reconstitution and prognostic markers is essential to limit morbidity and mortality after HSCT.

Interleukin-7 (IL-7) is a hematopoietic cytokine essential for de novo $\mathrm{T}$ cell development in the thymus and homeostatic peripheral expansion of T cells (4-6). IL-7 signals through the IL-7 receptor (IL-7R), a heterodimer consisting of the common $\gamma$-chain (CD132) and the high-affinity IL-7R $\alpha$-chain (IL-7R $\alpha$, CD127) (7). The IL-7R $\alpha$-chain is also used by Thymic Stromal Lymphopoetin, a cytokine promoting $\mathrm{TH} 2$ differentiation and Treg induction, and involved in allergic inflammation and autoimmunity (8-12).

Interleukin-7 receptor $\alpha$-chain is expressed on lymphocyte progenitors and on naïve and memory T cells, and its expression is strictly regulated during the different developmental stages of $\mathrm{T}$ cells with the highest expression on naïve $\mathrm{T}$ cells, a lower expression on memory $\mathrm{T}$ cells, and downregulation of IL-7R $\alpha$ upon development into effector T cells $(6,13)$. The critical role of the IL-7 pathway for human T cell homeostasis is illustrated by the fact that absence of a functioning IL-7R $\alpha$ leads to severe combined immunodeficiency with a T-B + NK + phenotype (14), while somatic gain-of-function mutations in IL-7R $\alpha$ may cause $\mathrm{T}$ - as well as B-cell acute lymphoblastic leukemia $(15,16)$.

Single nucleotide polymorphisms (SNPs) in the exons of the IL-7R $\alpha$, which give rise to non-conservative amino-acid substitutions, have been associated with several chronic inflammatory diseases. The rs6897932 SNP in the transmembrane region of the IL-7R $\alpha$ increases the risk of developing multiple sclerosis, ulcerative colitis, and sarcoidosis (17-20). In allogeneic HSCT, donor genotypes of SNPs influencing the structure of the extracellular part of IL-7R $\alpha$ have been associated with non-relapse mortality after allogeneic HSCT, in contrast to recipient genotypes that were not associated with outcomes (21-23).
In this study, we show that the donor genotype in IL-7R $\alpha$ rs6897932 influences the rate of immune reconstitution after allogeneic HSCT with impact on infections as well as acute GVHD (aGVHD) and chronic GVHD (cGVHD).

\section{MATERIALS AND METHODS}

\section{Patient Population}

We retrospectively studied patients undergoing allogeneic transplantation at the national HSCT center at Copenhagen University Hospital Rigshospitalet, Denmark, from 2004 to 2014. Inclusion criteria were first allogeneic HSCT, myeloablative conditioning (24), a matched sibling donor or an unrelated donor, and the use of bone marrow or peripheral blood as stem cell source.

Five-hundred twelve patients fulfilled the inclusion criteria. Deposited donor blood samples were available for 471 of these, and a donor SNP could be assigned for 460 patients (89.8\%), which were all included in the study. The included patients did not differ significantly from non-participants in terms of age, diagnosis, donor, conditioning regimen, graft type, cell dose/ kilogram, pre-transplant Karnofsky score, sex-mismatch, or cytomegalovirus (CMV) antibody status.

The study protocol was approved by the ethics committee of the Capital Region of Denmark (\#H-15006001), and written informed consent was obtained from all patients and/or their legal guardians.

\section{Patient Characteristics}

The study included 153 children and 307 adults with a median age of 26.3 years (range $0.3-63.0$ years). Diagnosis was acute myeloid leukemia $(n=136)$, acute lymphoblastic leukemia $(n=118)$, myelodysplastic syndrome $(n=51)$, chronic myeloid leukemia $(n=39)$, other malignancies $(n=28)$, or benign diseases $(n=88$, including 46 severe aplastic anemia and 24 primary immunodeficiencies). Donors were either fully human leukocyte antigen-A, -B, -C, -DR, and -DQ allele-matched sibling donors $(n=147)$, matched unrelated donors $(10 / 10$ match, $n=244)$, or mismatched unrelated donors $(9 / 10$ or $8 / 10$ match, $n=69)$. Bone marrow $(n=329)$ or G-CFS mobilized peripheral blood stem cells $(n=131)$ were used as stem cell source, and allografts were T cell replete. Conditioning regimens consisted of total body irradiation (TBI) plus cyclophosphamide or etoposide $(n=293)$, cyclophosphamide plus busulphane $(n=107)$, or other types 
of chemotherapy-based conditioning $(n=60)$. Conditioning included anti-thymocyte globulin (ATG) in 179 patients transplanted with an unrelated donor. GVHD prophylaxis consisted of Cyclosporine A plus methotrexate for $90 \%$ of patients. All patients were monitored weekly by PCR for viral infections (reactivation or primary infection) with CMV and Epstein-Barr virus (EBV) until day +90 post-HSCT and subsequently every second week. In case of increasing viral load, pre-emptive treatment with anti-viral medication [(Val)ganciclovir for CMV infection and Rituximab for EBV infection] was commenced along with tapering of immunosuppression.

\section{Detection of IL-7R $\alpha$ SNPs}

Blood from donors were collected before HSCT and stored at $-20^{\circ} \mathrm{C}$. Genomic DNA extraction was performed using Maxwell ${ }^{\mathrm{TM}} 16$ Blood DNA Purification Kit (Promega Biotech AB, Nacka, Sweden) as described by the manufacturer.

DNA was genotyped for $r$ s6897932 using a previously described multiplex bead-based assay (25). In brief, allele-specific primers were labeled in a primer extension using polymerase chain reaction-amplified SNP-sites as their target regions. The labeled primers were then hybridized to MicroPlex-xTAG beadsets for detection and counting on the Luminex platform (Luminex Corporation, Austin, TX, USA). We also included primers for the sex-specific amelogenin-gene ("AMELX" and "AMELY," respectively) to be able to define the sex of the donor as a quality control (26).

All donor samples were blinded to the technicians performing the analyzes. The IL-7R $\alpha$ SNP calling rates were $99.4 \%$, and $10 \%$ of samples were genotyped twice without discordance. Eight samples were excluded due to mismatch between sex according to sex determined by the amelogenin-gene and known donor sex.

\section{Immunological Parameters}

Absolute lymphocyte counts were measured as part of the clinical routine by particle counting using Sysmex XN flow cytometry. Total immunoglobulins (IgM, IgG, and IgA) were measured with turbidimetry using Cobas 8000, module c502.

$\mathrm{T}$ and $\mathrm{B}$ cells were counted 12 months after HSCT, and in addition measured after $1,2,3$, and 6 months in patients undergoing HSCT from 2008 to 2014 ( $n=283,62 \%)$. Peripheral blood samples were analyzed directly in a single-platform no-lyse-no-wash flow cytometry procedure. EDTA-anti-coagulated blood were incubated in Trucount tubes (Becton, Dickinson \& Company, Albertslund, Denmark) for quantification of lymphocyte subsets, and a panel of monoclonal antibodies (CD3-PerCP, CD3-FITC, CD4-FITC, CD8-PE, CD45-PerCP, and CD19-PE, all from BD) on a FC500 flow cytometer (Beckman Coulter, Copenhagen, Denmark). Lymphocytes were gated based on forward scatter and side scatter characteristics. Lymphocyte subsets were identified as CD3+ T cells, CD4+ T cells, CD8+ T cells, and CD45+ CD19+ $\mathrm{B}$ cells. The laboratory participates in the quality assurance program by the National External Quality Assessment Site (NEQAS).

\section{Statistical Analysis}

Kaplan-Meier estimates with log-rank tests were applied as an initial non-parametric analysis of the risk of complications and mortality. Next, a cause-specific Cox regression model was used to estimate the risk of aGVHD, cGVHD, viral reactivation, and time to lymphocyte recovery. Overall survival was analyzed further using Cox regression, while treatment-related mortality (TRM) and relapse were estimated using Fine-Gray competing risk regression model. For all analyzes, transplant-related characteristics that are main risk factors for the specific transplantrelated complications were included in the multivariable model for this outcome as indicated under results.

Linear regression analyzes were used to analyze associations with cell counts and immunoglobulin levels after 1 year. Longitudinal analysis of $\mathrm{T}$ cell counts were performed with a linear mixed model with random slope over time since transplantation and random intercept by patient for measurements from all patients without truncation due to death, relapse, retransplantation, or donor lymphocyte infusion within the first 360 days. All cell counts were $\log 10$-transformed; and measurements equal to $0(3.2 \%)$ were changed to $0.005 \times 10^{9} / \mathrm{L}$ corresponding to one half of the minimum value of the measurements. For the multivariable analysis, all potential co-variables were included in the model and analyzed with backwards elimination. The final model included recipient age, stem cell source, ATG, and the IL-7R $\alpha$ genotype. In an additional backwards elimination model, aGVHD and CGVHD were included as time-dependent variables and remained significant together with recipient age, stem cell source, ATG, and the IL-7R $\alpha$ genotypes.

To confirm these results regarding $\mathrm{T}$ cell counts in a model including patients, who experienced death, relapse, retransplantation, or donor lymphocyte infusion within the first 360 days, we performed a pattern mixture model including all patients and with truncation at time of the event. This model analyzed the cell counts in each stratum (defined by time of event/truncation) in turn using a standard linear mixed model. The mixed model contained a random intercept by patient and, whenever feasible due to enough data in a stratum, a random slope by time since transplantation. The IL-7R $\alpha$ genotypes were compared as major allele homozygotes (CC) versus heterozygotes and minor allele homozygotes combined (CT/TT) due to limited data within each stratum in the minor allele homozygous patients. Missing and truncated were similarly distributed in the genotype groups.

A two-sided $P$-value $<0.05$ was considered statistically significant. All statistical analyzes were performed using R statistical software version 3.2.3 (R Foundation for Statistical Computing, Vienna, Austria).

\section{RESULTS}

\section{IL-7R $\alpha$ Genotypes and Transplantation Characteristics}

The frequencies of the $r s 6897932$ genotype in donors [CC $=252$ (55.8\%), CT $=178(38.7 \%)$, and $\mathrm{TT}=30(6.5 \%)]$ corresponded to previously reported gene frequencies, and the distribution of genotypes met the criteria for Hardy-Weinberg equilibrium.

Table 1 shows the transplantation characteristics divided among the rs6897932 genotypes. No significant differences were found between patients in the three different groups. 
TABLE 1 | Transplantation characteristics by donor Interleukin-7 receptor $\alpha$-chain genotype rs6897932.

\begin{tabular}{|c|c|c|c|c|}
\hline Characteristics & CC $(n=252)$ & CT $(n=178)$ & TT $(n=30)$ & $P$-value \\
\hline \multicolumn{5}{|l|}{ Age at transplantation (years), median (range) } \\
\hline Recipients & $25.4(0.4-63.0)$ & $27.8(0.3-60.0)$ & $27.6(0.9-50.6)$ & 0.61 \\
\hline Donors & $34.0(2.8-71.6)$ & $33.0(1.1-59.5)$ & $35.6(16.1-60.8)$ & 0.27 \\
\hline \multicolumn{5}{|l|}{ Disease at transplantation, no. of patients (\%) } \\
\hline Acute myeoloid leukemia & $78(31 \%)$ & $50(28 \%)$ & $8(27 \%)$ & 0.89 \\
\hline Acute lymphoblastic leukemia & $62(25 \%)$ & $48(27 \%)$ & $8(27 \%)$ & \\
\hline Other malignancies & $65(26 \%)$ & $43(24 \%)$ & $10(33 \%)$ & \\
\hline Benign disorders & 47 (19\%) & $37(21 \%)$ & $4(13 \%)$ & \\
\hline \multicolumn{5}{|l|}{ Donor type, no. (\%) } \\
\hline HLA-identical. siblings & $78(31 \%)$ & 57 (32\%) & $12(40 \%)$ & 0.81 \\
\hline HLA-matched unrelated donors & $133(53 \%)$ & 97 (54\%) & $14(47 \%)$ & \\
\hline HLA-mismatched unrelated donors & $41(16 \%)$ & $24(13 \%)$ & $4(13 \%)$ & \\
\hline \multicolumn{5}{|l|}{ Stem cell source, no. (\%) } \\
\hline Bone marrow stem cells & $181(72 \%)$ & $130(73 \%)$ & $18(60 \%)$ & 0.34 \\
\hline Peripheral blood stem cells, G-CSF mobilized & $71(28 \%)$ & $48(27 \%)$ & $12(40 \%)$ & \\
\hline Total nucleated cell dose infused $\times 10^{6} / \mathrm{kg}$ recipient wt, median & 4 & 3.6 & 5 & 0.29 \\
\hline \multicolumn{5}{|l|}{ Conditioning regimen, no. of patients (\%) } \\
\hline $\mathrm{TBI}+\mathrm{CY}$ or Etoposide & $156(62 \%)$ & $116(65 \%)$ & $21(70 \%)$ & 0.61 \\
\hline Chemotherapy alone & $96(38 \%)$ & $62(35 \%)$ & $9(30 \%)$ & \\
\hline \multicolumn{5}{|l|}{ Anti-thymocyte globulin as part of conditioning regimen, no. (\%) } \\
\hline Yes & $105(42 \%)$ & $65(37 \%)$ & $9(30 \%)$ & 0.34 \\
\hline No & $147(58 \%)$ & $113(63 \%)$ & $21(70 \%)$ & \\
\hline \multicolumn{5}{|l|}{ Sex-mismatch (female donor to male recipient), no. (\%) } \\
\hline Yes & $37(15 \%)$ & 27 (15\%) & 7 (23\%) & 0.46 \\
\hline No & $215(85 \%)$ & $151(85 \%)$ & $23(77 \%)$ & \\
\hline \multicolumn{5}{|l|}{ CMV IgG mismatch, no. (\%) } \\
\hline Yes & $91(36 \%)$ & $61(34 \%)$ & $10(33 \%)$ & 0.86 \\
\hline No & 161 (64\%) & 117 (66\%) & 20 (67\%) & \\
\hline
\end{tabular}

\section{Donor rs6897932 Genotype and aGVHD}

251 patients $(54.6 \%)$ developed aGVHD with onset at median day $+24(+6$ to +106$)$ post-HSCT; grades III-IV aGVHD were seen in 42 patients $(9.1 \%)$. The risk of grades III-IV aGVHD was significantly increased in donors with one or two copies of the T allele in $r s 6897932$ (12.5\% for CT/TT versus $6.3 \%$ for CC, $P=0.023$ ) (Figure 1; Table S1 in Supplementary Material). This was confirmed in a multivariable Cox regression after adjustment for recipient age, donor type (matched sibling donor/matched unrelated donor/mismatched unrelated donor), stem cell source, cell dose/kilogram, TBI-based conditioning, ATG, and sexmismatch $(\mathrm{HR}=2.0,95 \% \mathrm{CI}=1.1-3.8, P=0.036$ for TT/CT compared with the CC genotype).

\section{Donor rs6897932 Genotype and cGVHD}

Extensive cGVHD occurred in 118 patients (25.7\%) at median day +201 ( +42 to $+2,088)$, and this was significantly associated with donor $r s 6897932$ genotype with a step-wise increased risk of cGVHD for each T allele (CC: $21.8 \%$, CT: $27.0 \%$, and TT: $50.0 \%$, $P=0.0031$ ) (Figure 2; Table S1 in Supplementary Material). The risk of extensive cGVHD was significantly increased for the TT versus CC genotype in a multivariable Cox regression adjusting for recipient age, donor type (matched sibling donor/matched unrelated donor/mismatched unrelated donor), stem cell source, cell dose/kilogram, TBI-based conditioning, ATG, and sexmismatch $(\mathrm{HR}=2.0,95 \% \mathrm{CI}=1.1-3.6, P=0.025)$.

To address if the effect of the donor genotype on chronic GVHD was mediated by the increased risk of aGVHD, we included
aGVHD in a Cox regression model also adjusting for recipient age, donor type, stem cell source, cell dose/kilogram, TBI-based conditioning, ATG, and sex-mismatch. In this modified model, the donor $r s 6897932$ genotype remained an independent risk factor of extensive cGVHD $(\mathrm{HR}=1.9,95 \% \mathrm{CI}=1.0-3.5, P=0.035)$.

\section{Donor rs6897932 Genotype and Viral Infections}

123 patients (26.7\%) developed therapy-requiring CMV infection at median day +49 post-HSCT, and 34 patients $(7.4 \%)$ developed therapy-requiring EBV infection at median day +57 .

Donor $r s 6897932$ TT genotype was associated with a higher occurrence of CMV infection compared with CC (CC: $23.8 \%$, CT: $31.4 \%$, and TT: $43.3 \%, P=0.053$ ) (Figure 3; Table S1 in Supplementary Material). The risk of CMV infection post-HSCT was significantly increased with $\mathrm{HR}=2.3(95 \% \mathrm{CI}=1.2-4.3$, $P=0.0083$ ) for TT versus CC genotype in a multivariable Cox regression model adjusting for recipient age, donor type (matched sibling donor/matched unrelated donor/mismatched unrelated donor), stem cell source, cell dose, TBI-based conditioning, ATG and CMV mismatch between donor and recipient $(\mathrm{D}-\mathrm{R}+$ or $\mathrm{D}+\mathrm{R}-)$. No association with EBV infection was observed.

\section{Donor rs6897932 Genotype and Early Lymphocyte Reconstitution}

Lymphocyte recovery with $>10^{9}$ lymphocytes/L occurred in 427 patients (92.8\%) within the first year post-HSCT. There was 


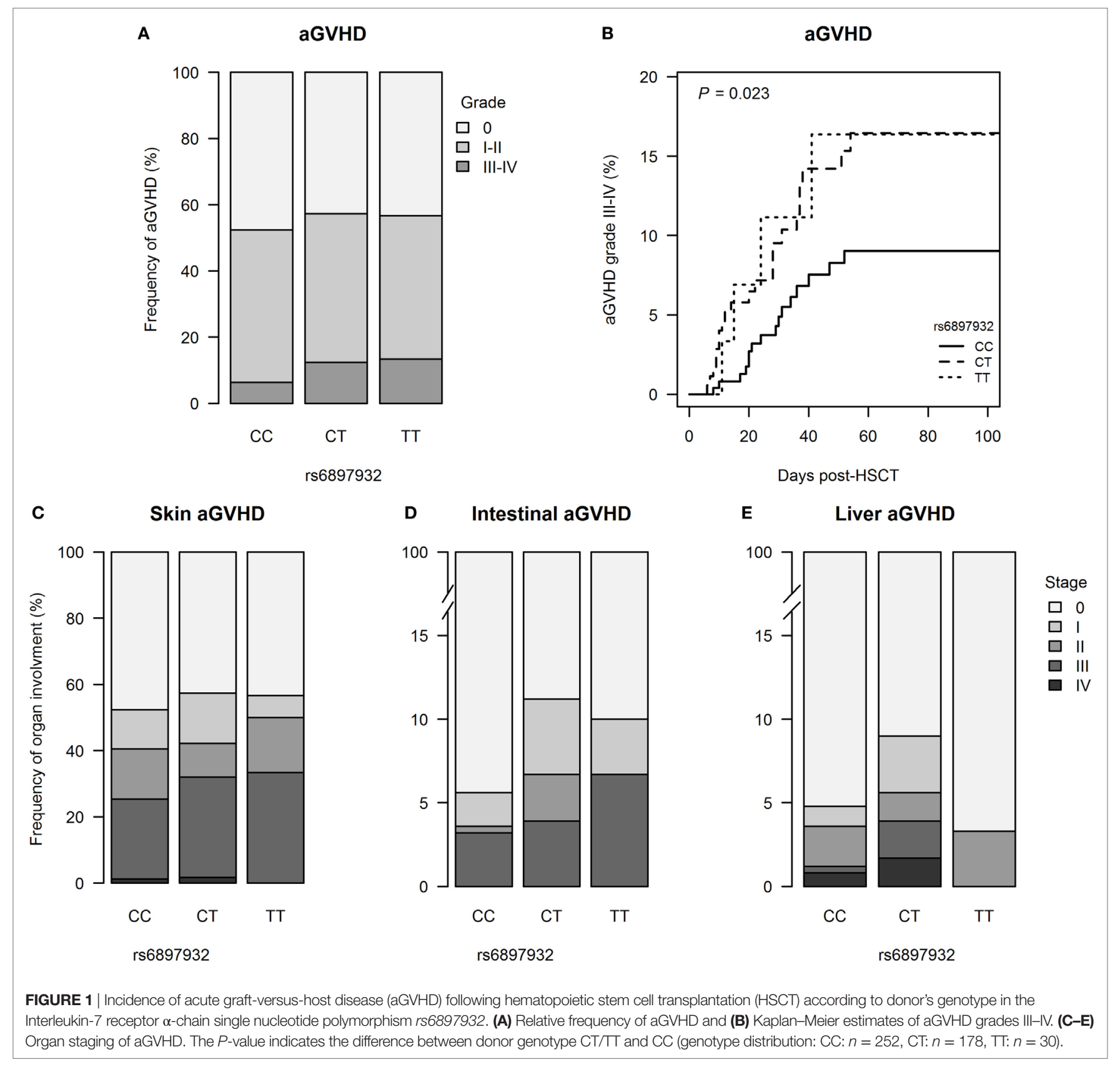

no association between donor rs6897932 genotype and time to lymphocyte recovery.

We further investigated the impact $r s 6897932$ on recovery of $\mathrm{T}$ and B lymphocyte subsets within 1 year post-HSCT. Patients were excluded from the analysis in case of death, relapse, retransplantation, or donor lymphocyte infusion from the date of the event.

First, we studied the impact on immune reconstitution in a linear mixed model only including patients, who did not experience an event within the first 360 days $(n=212)$. In an univariable model, the donor $r s 6897932$ genotype TT was associated with significantly increased CD3+, CD4+, and CD8+ T cells at day +60 compared with the CC genotype (Figure 4). This was confirmed in the multivariable model, where the donor TT genotype was associated with an increased number of T cell subsets (CD3+: $109 \%$ increase, $P=0.0096$; CD $4+: 64 \%$ increase, $P=0.038$; CD8+: $133 \%$ increase, $P=0.011$ ) at day +60 compared with the CC genotype, after adjustment for age, stem cell source, and ATG (Table 2). These results were similar, when also adjusting for the immunosuppressive effect of aGVHD and cGVHD by including them as time-dependent co-variables in this model $(P=0.0079$, $P=0.030$, and $P=0.0096$, respectively).

Next, we investigated the significance of IL-7R $\alpha$ donor genotypes in a pattern mixture model with truncation due to death, relapse, retransplantation, or donor lymphocyte infusion to confirm the first results in a cohort including patients who experienced an event $(n=268)$. At each time of follow-up, 

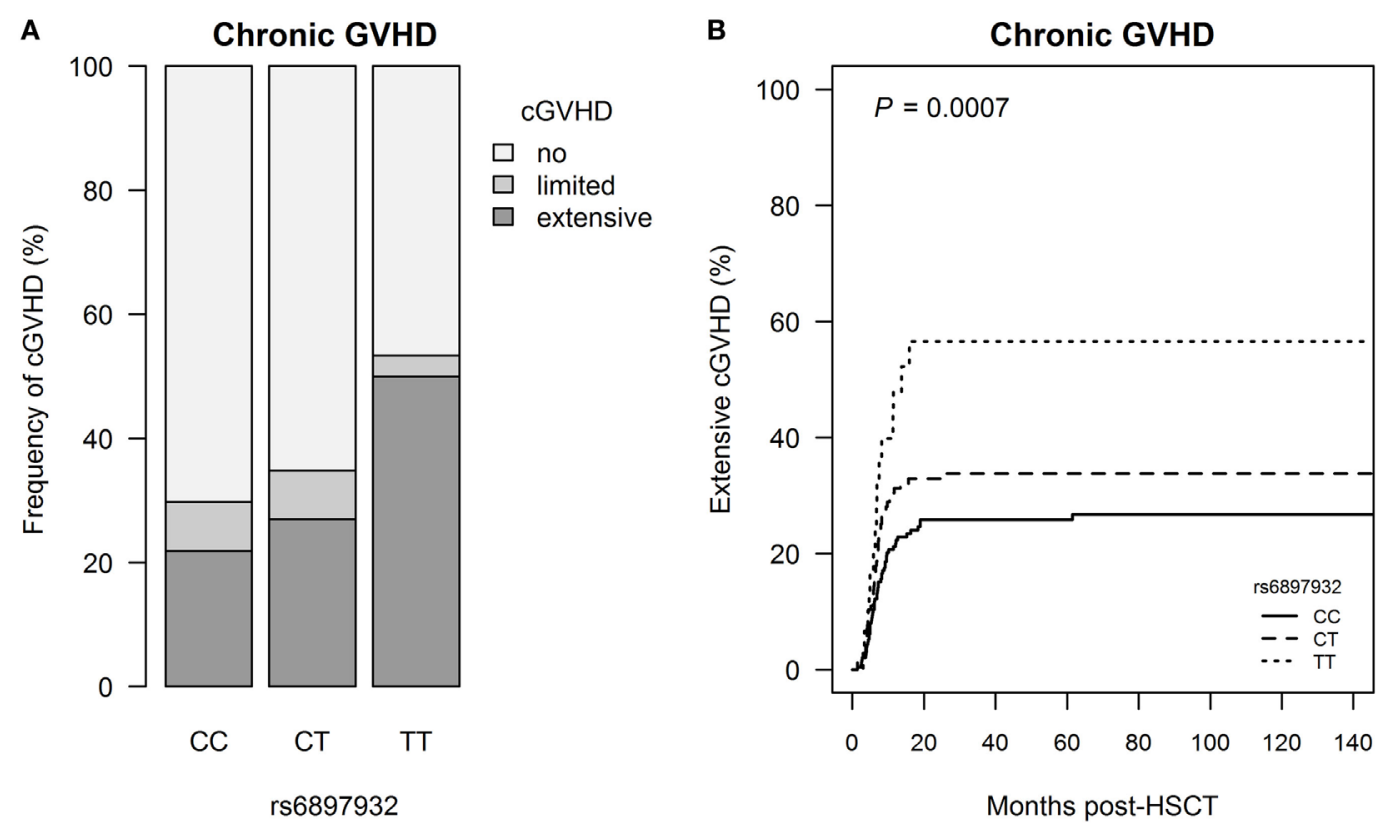

FIGURE 2 | Incidence of chronic graft-versus-host disease (cGVHD) following hematopoietic stem cell transplantation (HSCT) according to donor's genotype in the Interleukin-7 receptor $\alpha$-chain single nucleotide polymorphism rs6897932. (A) Relative frequency of CGVHD and (B) Kaplan-Meier estimates of extensive cGVHD. The $P$-value indicates the difference between donor genotype TT and CC (genotype distribution: CC: $n=252$, CT: $n=178, T$ T: $n=30$ ).

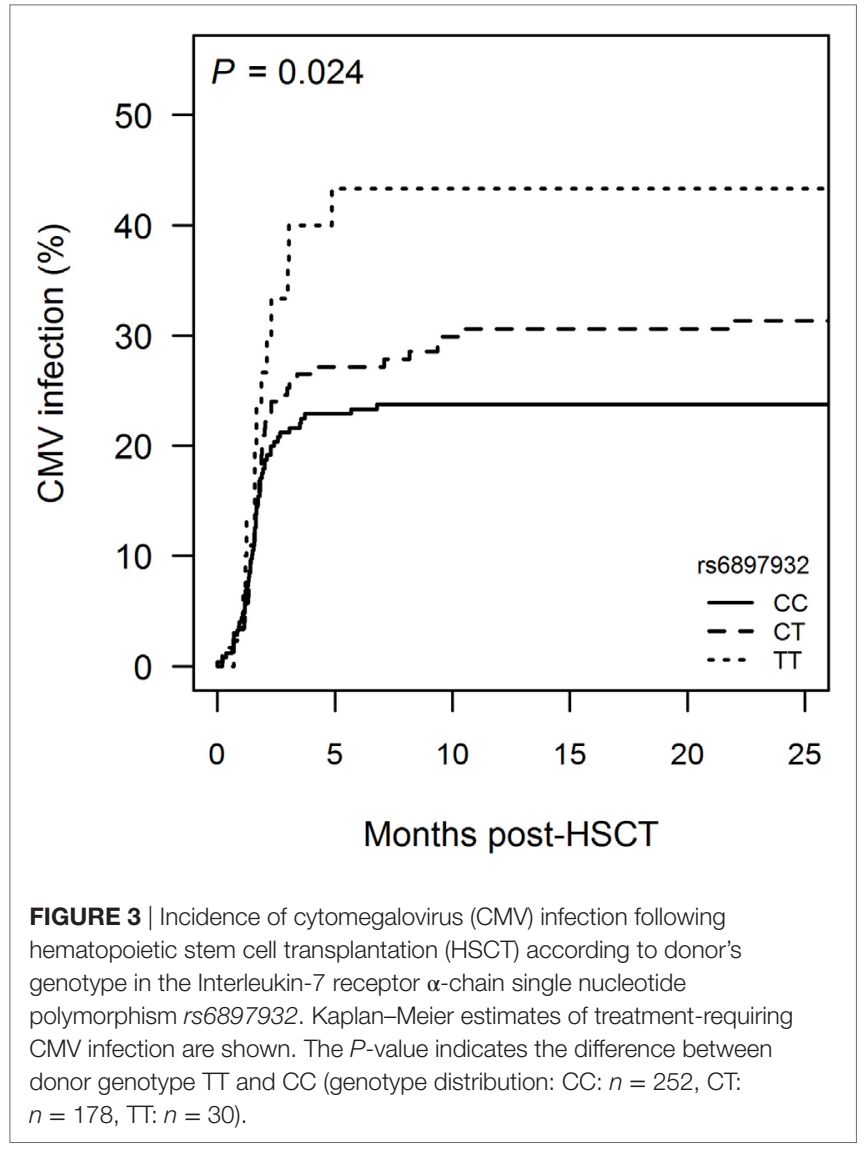

the expected change in median cell count were estimated and compared between the genotype groups. The two groups CT and TT were merged to be able to estimate all parameters, due to the limited number of donors with the TT genotype. In this model, no significant difference between cell counts for the rs6897932 genotype was found at any time point, most likely due to the limited data in each strata. Notably, missing and truncated patients were similarly distributed in the two genotype-defined groups.

\section{Donor rs6897932 Genotype and Late Immunity}

We next assessed the major immune parameters 1 year after HSCT. Measurements of T and B cells were available in 233 (72.6\%) patients having no events before this time point. There was no difference in cell counts of any lymphocyte subsets according to the $r s 6897932$ genotype in a linear regression model both before and after adjustment for age, stem cell source, and ATG (Figures 5A-D; Table 2).

We looked into the level of immunoglobulins to evaluate the functional interaction between $\mathrm{T}$ and $\mathrm{B}$ cells. The donor rs6897932 TT genotype was associated with significantly lower levels of IgG and IgM compared to the CC genotype 1 year postHSCT (Figures 5E-G), although no difference was observed before transplantation. This finding remained significant for IgG in a multivariable model adjusting for age, stem cell source, and ATG $(P=0.027)$. However, this decrease in immunoglobulin levels was also strongly associated with occurrence of aGVHD and cGVHD, suggesting that the immunosuppressive effect 


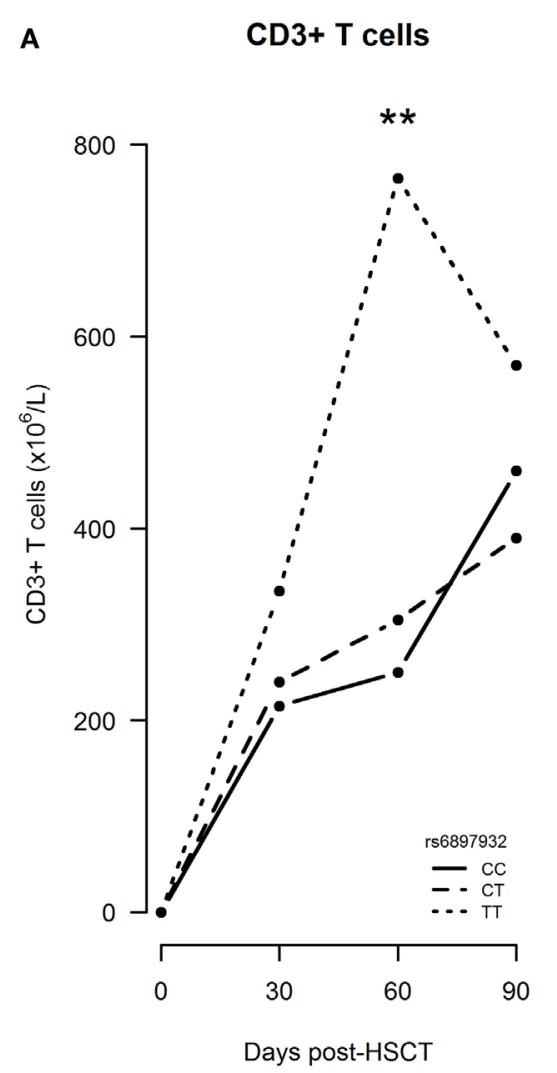

B

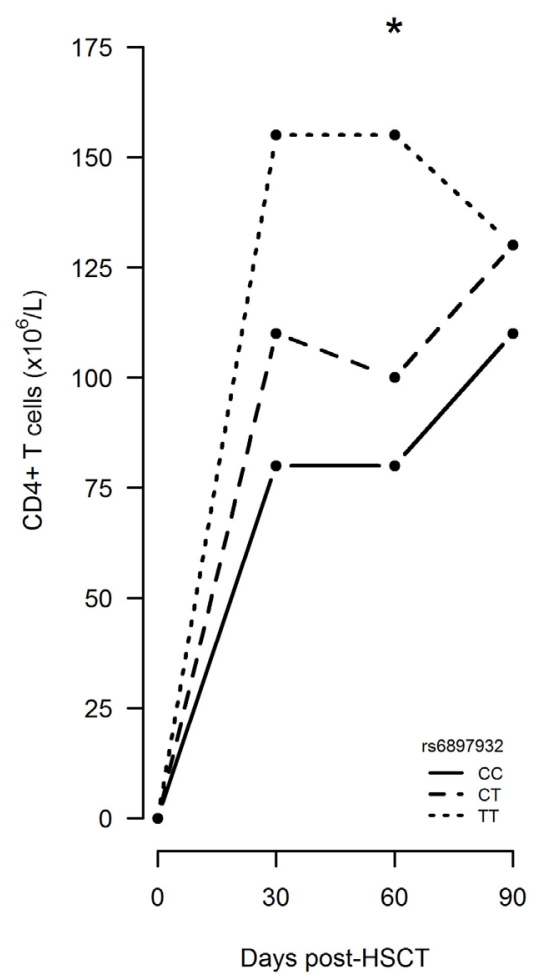

C

CD8+ T cells

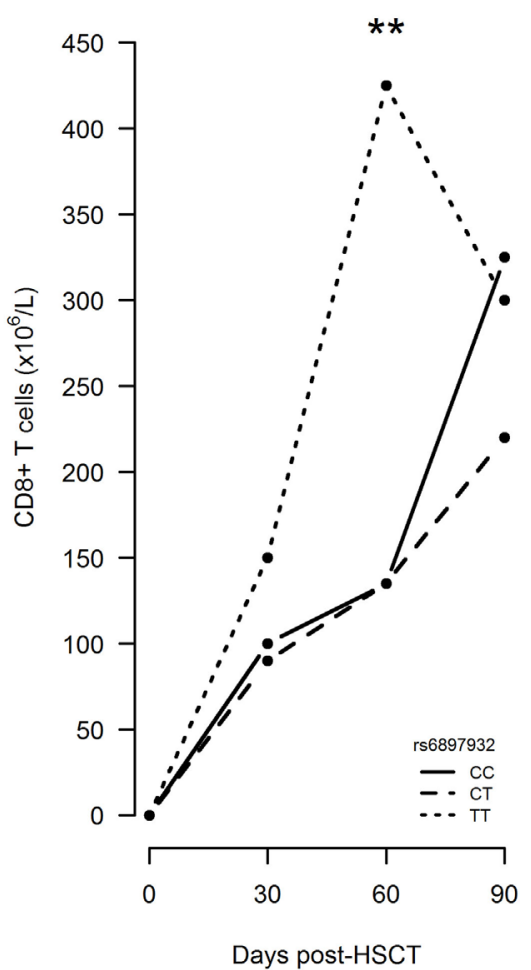

FIGURE 4 | Early immune reconstitution following hematopoietic stem cell transplantation (HSCT) according to donor's genotype in the Interleukin-7 receptor $\alpha$-chain single nucleotide polymorphism rs6897932. (A-C) Median CD3+, CD4+, and CD8+ T cell counts from time of transplantation to 3 months post-HSCT. The $P$-values indicate the difference between donor genotype $\Pi \mathrm{T}$ and $\mathrm{CC}$ at the specific time point in a longitudinal linear mixed model $\left({ }^{\star} P<0.05\right.$, $\left.{ }^{\star \star} P<0.01\right)$ (genotype distribution: CC: $n=108$, CT: $n=86$, TT: $n=18$ ).

TABLE 2 | Longitudinal T cell reconstitution by donor Interleukin-7 receptor $\alpha$-chain genotype.

\begin{tabular}{cccccccccc}
\multicolumn{3}{c}{ Univariable model [estimate $(95 \% \mathrm{Cl})]$} & & \multicolumn{3}{c}{ Multivariable model [estimate $(95 \%$ Cl)] } \\
\hline CC & CT & $\begin{array}{l}P \text {-value (CT } \\
\text { versus CC) }\end{array}$ & TT & $\begin{array}{l}P \text {-value (TT } \\
\text { versus CC) }\end{array}$ & CC & CT & $\begin{array}{l}P \text {-value (CT } \\
\text { versus CC) }\end{array}$ & TT & $\begin{array}{c}P \text {-value } \\
\text { (TT versus } \\
\text { CC) }\end{array}$
\end{tabular}

\begin{tabular}{|c|c|c|c|c|c|c|c|c|c|c|}
\hline \multicolumn{11}{|c|}{ Day +30 } \\
\hline CD3+ & 1.0 & $0.90(0.61-1.32)$ & 0.59 & $1.37(0.71-2.64)$ & 0.34 & 1.0 & $0.94(0.67-1.33)$ & 0.75 & $1.04(0.57-1.90)$ & 0.89 \\
\hline CD4+ & 1.0 & $0.97(0.69-1.37)$ & 0.85 & $1.68(0.93-3.05)$ & 0.088 & 1.0 & $1.03(0.77-1.38)$ & 0.86 & $1.27(0.76-2.10)$ & 0.36 \\
\hline CD8+ & 1.0 & $0.91(0.61-1.38)$ & 0.67 & $1.19(0.58-2.44)$ & 0.63 & 1.0 & $0.95(0.64-1.41)$ & 0.79 & $0.96(0.48-1.92)$ & 0.92 \\
\hline \multicolumn{11}{|c|}{ Day +60} \\
\hline CD3+ & 1.0 & $1.16(0.81-1.67)$ & 0.42 & 2.37 (1.29-4.35) & 0.006 & 1.0 & $1.20(0.86-1.67)$ & 0.30 & $2.09(1.20-3.66)$ & 0.0097 \\
\hline CD4+ & 1.0 & $1.08(0.78-1.50)$ & 0.63 & $1.94(1.13-3.37)$ & 0.017 & 1.0 & $1.13(0.86-1.50)$ & 0.38 & $1.64(1.03-2.61)$ & 0.038 \\
\hline CD8+ & 1.0 & $1.24(0.83-1.86)$ & 0.29 & $2.53(1.29-4.96)$ & 0.007 & 1.0 & $1.26(0.85-1.86)$ & 0.24 & $2.33(1.21-4.47)$ & 0.011 \\
\hline \multicolumn{11}{|c|}{ Day +90} \\
\hline CD3+ & 1.0 & $1.02(0.73-1.44)$ & 0.89 & $1.36(0.70-2.64)$ & 0.36 & 1.0 & $1.02(0.74-1.39)$ & 0.91 & $1.22(0.66-2.27)$ & 0.53 \\
\hline CD4+ & 1.0 & 0.99 (0.74-1.34) & 0.97 & $1.53(0.85-2.73)$ & 0.16 & 1.0 & $1.01(0.78-1.30)$ & 0.96 & $1.28(0.77-2.15)$ & 0.34 \\
\hline CD8+ & 1.0 & $1.03(0.71-1.51)$ & 0.86 & 1.35 (0.64-2.83) & 0.43 & 1.0 & $1.03(0.71-1.48)$ & 0.89 & $1.26(0.61-2.59)$ & 0.53 \\
\hline \multicolumn{11}{|c|}{ Day +180 } \\
\hline CD3+ & 1.0 & $1.00(0.74-1.36)$ & 0.99 & $0.94(0.55-1.59)$ & 0.81 & 1.0 & 0.99 (0.74-1.33) & 0.95 & $0.86(0.52-1.43)$ & 0.56 \\
\hline CD4+ & 1.0 & $0.98(0.75-1.28)$ & 0.86 & $1.13(0.71-1.80)$ & 0.61 & 1.0 & $0.97(0.76-1.23)$ & 0.80 & $1.01(0.66-1.53)$ & 0.97 \\
\hline CD8+ & 1.0 & $0.94(0.66-1.35)$ & 0.74 & $0.80(0.43-1.49)$ & 0.48 & 1.0 & $0.93(0.66-1.33)$ & 0.71 & $0.76(0.41-1.40)$ & 0.38 \\
\hline \multicolumn{11}{|c|}{ Day +360} \\
\hline CD3+ & 1.0 & $0.97(0.72-1.31)$ & 0.83 & $0.93(0.53-1.63)$ & 0.79 & 1.0 & $0.94(0.71-1.24)$ & 0.67 & $0.91(0.54-1.55)$ & 0.74 \\
\hline CD4+ & 1.0 & $0.92(0.67-1.25)$ & 0.59 & $1.04(0.58-1.86)$ & 0.90 & 1.0 & $0.89(0.68-1.16)$ & 0.38 & $0.98(0.59-1.63)$ & 0.95 \\
\hline CD8+ & 1.0 & 0.98 (0.69-1.39) & 0.90 & $0.87(0.45-1.66)$ & 0.67 & 1.0 & $0.95(0.68-1.34)$ & 0.77 & $0.86(0.45-1.63)$ & 0.64 \\
\hline
\end{tabular}

Significant associations are written in bold. 

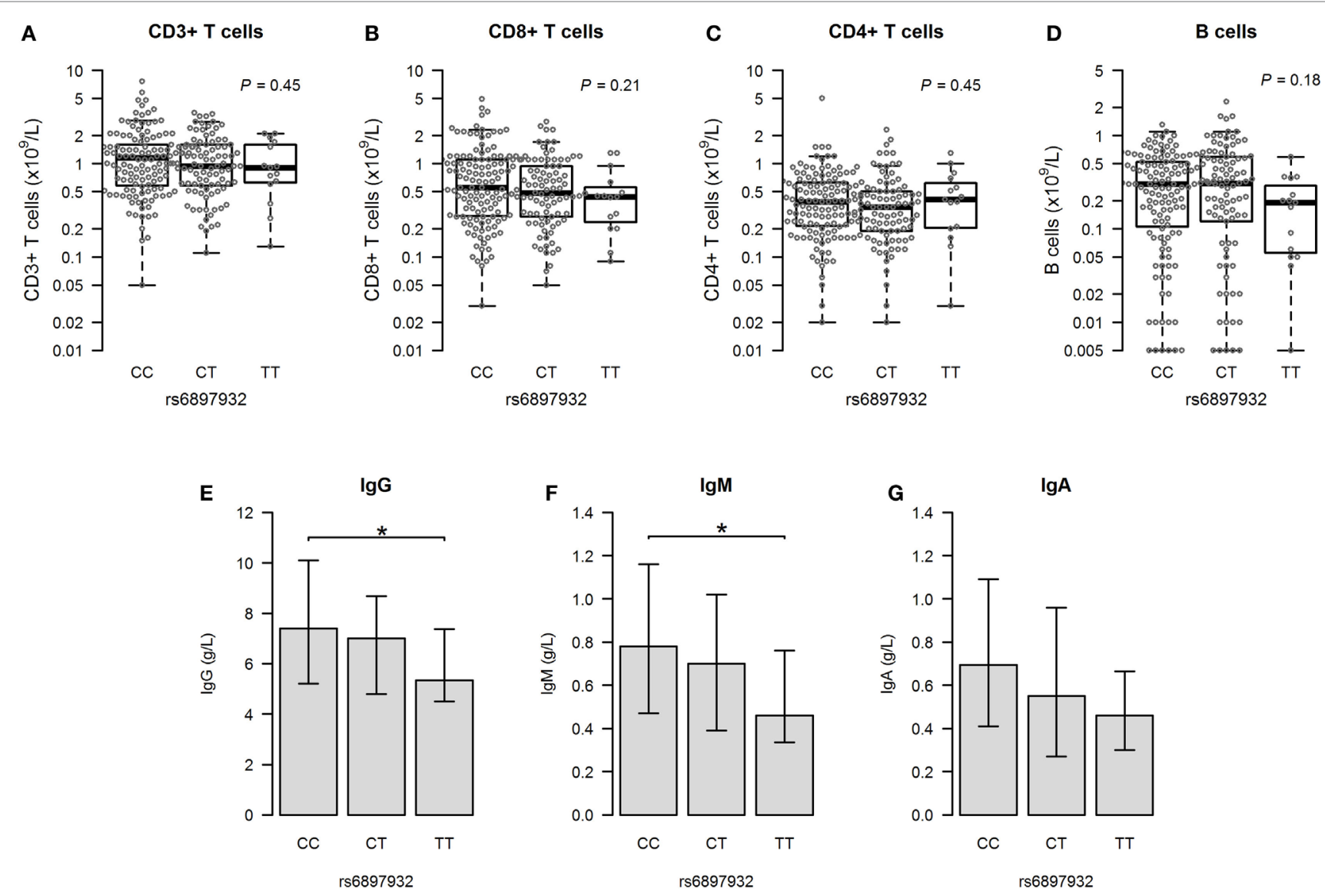

FIGURE 5 | Immunity at 1 year post-hematopoietic stem cell transplantation according to donor's genotype in the Interleukin-7 receptor $\alpha$-chain single nucleotide polymorphism rs6897932. (A-D) Total counts of CD3+, CD8+, and CD4+ T cells and CD19+ B cells. (E-G) Plasma levels of immunoglobulins (median plus quartiles). The $P$-values indicate the difference between donor genotype TT and CC $\left.{ }^{\star} P<0.05\right)$ (genotype distribution: CC: $n=128, \mathrm{CT}: n=90, \pi$ : $\left.n=15\right)$.

of $r$ 66897932 on late immunity might be mediated through an increased allo-response.

\section{Donor rs6897932 Genotype and Mortality}

We next investigated whether the rs6897932 donor genotype also influenced post-transplant mortality. 156 patients $(33.9 \%)$ died within the follow-up time of 6.9 years (range: 1.9-12.8). Of patients transplanted for a malignant disease, 78 patients $(21.0 \%)$ died of TRM and 81 patients $(21.8 \%)$ relapsed.

Donor carriage of the rs6897932 CT genotype was associated with inferior overall survival in an univariable Cox regression model ( $\mathrm{HR}=1.50, P=0.013$ ) (Figure 6A; Table $\mathrm{S} 1$ in Supplementary Material) as well as in a multivariable model adjusting for recipient age, diagnosis, donor type, stem cell source, TBI-based conditioning, and ATG (HR $=1.7$ for CT versus CC genotype, $95 \% \mathrm{CI}=1.2-2.3, P=0.0027)$.

In a competing risk model, donor rs6897932 CT genotype was associated with increased TRM in a univariable model (cumulative incidence estimates: $\mathrm{CC}=14.3 \%, \mathrm{CT}=35.0$, $\mathrm{TT}=19.6 \%$, $P=0.00022$ for CT versus CC genotype), but not with the risk of relapse $(P=0.35)$ (Figures 6B,C; Table S1 in Supplementary
Material). The significant association with TRM was confirmed in a multivariable competing risk model adjusted for recipient age, donor type, stem cell source, TBI-based conditioning, and ATG $(\mathrm{HR}=2.3,95 \% \mathrm{CI}=1.3-4.0, P=0.0047$ for $\mathrm{CT}$ versus $\mathrm{CC})$. We were not able to demonstrate a significant effect of TT homozygosity on TRM most likely reflecting the low prevalence of this genotype.

\section{DISCUSSION}

Despite the marked improvements during the recent years, allogeneic HSCT is still challenged by severe treatment-related complications (27). Both aGVHD and cGVHD cause significant morbidity and mortality after HSCT, and the long-term immunosuppressive treatment of these complications may have limited efficacy although still hampering the immune responses toward infections and the remaining leukemic cells (28). Thus, identification of risk factors for development of alloreactivity and immune dysfunction may be an important step toward a more effective risk stratification to prevent these complications.

Our data show that donor rs6897932 TT genotype in the IL-7R $\alpha$ is associated with increased risk of both aGVHD and 

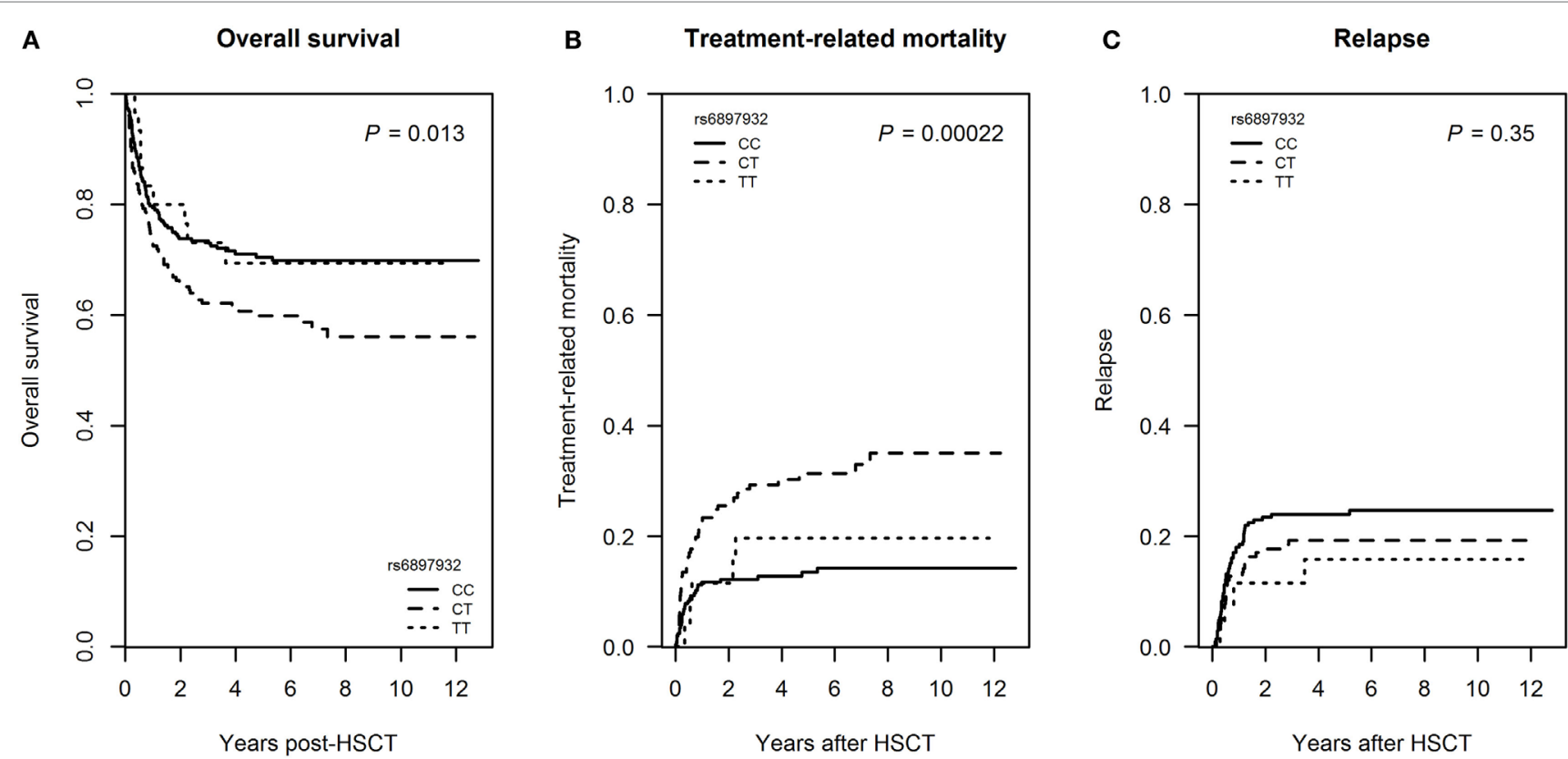

FIGURE 6 | Mortality following hematopoietic stem cell transplantation (HSCT) according to donor's genotype in the Interleukin-7 receptor $\alpha$-chain single nucleotide polymorphism rs6897932. (A) Overall survival, (B) treatment-related mortality (TRM), and (C) relapse frequency. Overall survival is estimated by Kaplan-Meier, while TRM and relapse are estimated by a Fine-Gray competing risk model. The $P$-values indicate the difference between donor genotype CT and CC (genotype distribution: CC: $n=252$, CT: $n=178$, TT: $n=30$ ).

cGVHD, CMV infection, and faster reconstitution of T cells. These results indicate that genotyping of $r 6897932$ could help to individualize conditioning regimens and GVHD prophylaxis, or potentially be included as a supplementary criteria for donor selection along with HLA-typing. As alloreactivity and the graftversus-leukemia effect are often closely associated (27), it is of particular interest that the impact of the rs6897932 genotype is restricted to treatment-related complications with no significant impact on relapse.

The rs6897932 SNP has been studied previously in lowpowered or heterogeneous multicenter studies with conflicting results concerning aGVHD and mortality $(21-23,29,30)$. A major strength of the present study is the large number of HSCT patients studied within a single institution with an ethnically homogeneous population and a uniform registration of complications. However, in comparison with genetic studies linking candidate SNPs to development of disease in general, our cohort is relatively small and results should be taken with caution, especially considering the low frequency of the risk genotype.

Interleukin-7 is a cytokine with effects on both peripheral expansion of $\mathrm{T}$ cells and thymic $\mathrm{T}$ cell production that is known to decline with age $(31,32)$. Accordingly, we found it important to address age-related differences in the impact of the IL-7R $\alpha$ SNP. In an age-stratified analysis, we found similar associations with clinical outcomes and $\mathrm{T}$ cell reconstitution in adult and pediatric patients suggesting that the effects of the genotype were independent on age-related changes in thymic function. In line with this, the IL-7R $\alpha$ SNP appeared to affect T cell numbers at an early stage before day 100 where thymic output in the form of $\mathrm{T}$ cell receptor excision circles cannot be detected (33-35), suggesting that $r s 6897932$ is mainly affecting the peripheral expansion of $\mathrm{T}$ cells of importance for both children and adults in the early post-transplant period.

The biological background for the impact of $r s 6897932$ on immune dysregulation in allo- and autoimmunity has been addressed previously. Studies in conditions with elevated IL-7 levels, due to lymphopenia or pharmacologic administration of IL-7, indicate that IL-7 in high concentrations may enhance the proliferative responses even to weak self-antigens (36-38). Therefore, it is likely that IL-7 may also drive peripheral expansion of naïve alloreactive $\mathrm{T}$ cell clones early after HSCT, where IL-7 levels are highly increased (39-41). Furthermore, recent studies suggest that IL-7 specifically enhances the proliferation of pro-inflammatory $\mathrm{T}$ cell subsets $(42,43)$ and reduce the functional capacity of regulatory $\mathrm{T}$ cells to suppress proliferation and cytokine production (44). In line with this, elevated IL-7 levels are associated with development of aGVHD after myeloablative HSCT and is increased in autoimmune diseases $(39-41,45)$.

The mechanism by which rs6897932 impacts outcome of HSCT is most likely related to an altered degree of binding of IL-7 to soluble IL-7R (sIL-7R). The T allele in $r s 6897932$ causes an amino-acid substitution in the transmembrane region of the IL-7R $\alpha$ gene which reduces alternative splicing of this domain. This process results in increased expression of membrane-bound IL-7R and decreased generation of sIL-7R $(46,47)$. Since sIL-7R acts as an inhibitor of IL-7 signaling in vitro (48), rs6897932 may affect IL-7 activity not only by diminishing sIL-7R levels, but also through increased expression of membrane-bound IL-7R $\alpha$.

Several lines of evidence suggest that the T allele of $r s 6897932$ increases IL-7 activity. First, the T allele is associated with faster 
$\mathrm{CD} 3+, \mathrm{CD} 4+$, and CD8+ T cell reconstitution early post-HSCT as shown here. These results correspond to studies in $\mathrm{T}$ cell depletion caused by human immunodeficiency virus, where the rs6897932 $\mathrm{T}$ allele and low-sIL-7R levels were associated with a more rapid CD4+ T cell recovery after anti-retroviral treatment (49). Furthermore, rs6897932 T allele has been associated with increased intracellular STAT-5 signaling in CD4+ T cells after in vitro stimulation with IL-7, resulting in increased cellular proliferation (50). In allogeneic HSCT, the increased homeostatic proliferation and survival of $\mathrm{T}$ cells from donors with the rs6897932 TT genotype are likely a contributing reason for the increased risk of GVHD observed here.

Secondly, the $\mathrm{T}$ allele is associated with reduced plasma levels of sIL-7R that are related to $\operatorname{aGVHD}(30,51)$. This is, however, in contrast to the findings in chronic inflammatory diseases, where the rs6897932 C allele and elevated sIL-7R levels have been identified as risk factors for developing multiple sclerosis, ulcerative colitis, sarcoidosis, inhalation allergy, and type 1 diabetes (17-20, 52-57). The explanation for this apparent inconsistency may relate to the limited levels of IL-7 seen in these autoimmune conditions compared with the HSCT setting, where IL-7 levels are many-fold above normal levels. A recent study suggested that sIL-7R is inhibitory at short-term, while overall potentiating the bioavailability of IL-7 by protecting the cytokine from consumption (58). In HSCT, however, the scenario is much different due to the supra-physiological levels of IL-7 in combination with severely depressed sIL-7R levels in the early post-transplant period (30, 51). Under these extreme conditions, even a short-term inhibition mediated by high sIL-7R may be enough to protect against alloreactivity, and thereby explain the lower incidence of GVHD in transplantations with a donor CC genotype.

Recent studies also suggest an importance of IL-7R $\alpha$ mediated signals for normal human B cell production (59), although patients with SCID caused by a defect IL-7R $\alpha$ signaling have normal B cell numbers (14). Our results do not suggest an association between IL-7R $\alpha$ SNPs and quantitative B cell reconstitution following HSCT, but show significantly decreased IgG levels after 1 year in patients transplanted with the rs6897932 TT genotype. This could not be related to a difference in $\mathrm{T}$ or B cell counts that were similar among the genotypes at this time point, although a functional impact on $\mathrm{T}$ cell subsets required for isotype switch and antibody production cannot be excluded. Importantly, however, our multivariable analysis suggested that the effect of this genotype on immunoglobulin levels may be mediated through cGVHD, suppressing bone marrow function (including the plasma cells) and thymopoiesis directly as well as indirectly by its immunosuppressive treatment (60). A potential confounding factor for these findings could be the administration of Rituximab for EBV infection, although this is most likely a minor factor in

\section{REFERENCES}

1. Storek J, Gooley T, Witherspoon RP, Sullivan KM, Storb R. Infectious morbidity in long-term survivors of allogeneic marrow transplantation is associated with low CD4 T cell counts. Am J Hematol (1997) 54:131-8. doi:10.1002/ (SICI) 1096-8652(199702)54:2<131::AID-AJH6>3.0.CO;2-Y

2. Kim DH, Sohn SK, Won DI, Lee NY, Suh JS, Lee KB. Rapid helper T-cell recovery above $200 \times 10^{6} / 1$ at 3 months correlates to successful transplant our study due the low numbers of patients receiving treatment and the equal distribution of EBV infection among the different rs6897932 genotypes.

In conclusion, we have presented solid evidence that the donor $r s 6897932$ genotype of the IL-7R $\alpha$ predicts aGVHD and cGVHD, CMV infection and TRM following allogeneic HSCT, without altering the risk of relapse. The biological background for the impact of this SNP may be alterations in the levels of soluble and membrane-bound IL-7R leading to stronger IL-7 signaling. Prospective studies should address the role of IL-7R genotyping as part of the donor selection process to reduce the incidence of treatment-related complications and its application as a pretransplant biomarker identifying patients at risk and guiding prophylactic treatment.

\section{ETHICS STATEMENT}

This study was carried out in accordance with the recommendations of the ethics committee of the Capital Region of Denmark. All subjects and/or their legal guardians gave written informed consent in accordance with the Declaration of Helsinki.

\section{AUTHOR CONTRIBUTIONS}

$\mathrm{KK}, \mathrm{AP}, \mathrm{LR}$, and $\mathrm{KM}$ conceived and designed the study. $\mathrm{KK}, \mathrm{CH}$, $\mathrm{HS}$, and KM collected the donor samples and the clinical data. $\mathrm{CE}$ performed the genotyping. KK and KM analyzed the data and drafted the manuscript. All authors revised the manuscript.

\section{ACKNOWLEDGMENTS}

We thank Pia Meinke (Institute for Inflammation Research, Copenhagen University Hospital Rigshospitalet) for excellent technical assistance in the laboratory and Kathrine Grell (Department of Pediatrics and Adolescent Medicine, Copenhagen University Hospital Rigshospitalet) for statistical assistance with the immune recovery analyzes.

\section{FUNDING}

This study was supported by The Research Council at Rigshospitalet (\#R85-A3157) and the Danish Childhood Cancer Foundation (\#2015-30).

\section{SUPPLEMENTARY MATERIAL}

The Supplementary Material for this article can be found online at https://www.frontiersin.org/articles/10.3389/fimmu.2018.00109/ full\#supplementary-material. outcomes after allogeneic stem cell transplantation. Bone Marrow Transplant (2006) 37:1119-28. doi:10.1038/sj.bmt.1705381

3. Ferrara JLM, Levine JE, Reddy P, Holler E. Graft-versus-host disease. Lancet (2009) 373:1550-61. doi:10.1016/S0140-6736(09)60237-3

4. Plum J, De Smedt M, Leclercq G, Verhasselt B, Vandekerckhove B. Interleukin-7 is a critical growth factor in early human T-cell development. Blood (1996) 88:4239-45. 
5. Fry TJ, Mackall CL. The many faces of IL-7: from lymphopoiesis to peripheral T cell maintenance. J Immunol (2005) 174:6571-6. doi:10.4049/ jimmunol.174.11.6571

6. Carrette F, Surh CD. IL-7 signaling and CD127 receptor regulation in the control of T cell homeostasis. Semin Immunol (2012) 24:209-17. doi:10.1016/j. smim.2012.04.010

7. Jiang Q, Li WQ, Aiello FB, Mazzucchelli R, Asefa B, Khaled AR, et al. Cell biology of IL-7, a key lymphotrophin. Cytokine Growth Factor Rev (2005) 16:513-33. doi:10.1016/j.cytogfr.2005.05.004

8. Reche PA, Soumelis V, Gorman DM, Clifford T, Liu M, Travis M, et al. Human thymic stromal lymphopoietin preferentially stimulates myeloid cells. $J$ Immunol (2001) 167:336-43. doi:10.4049/jimmunol.167.1.336

9. Ziegler SF, Artis D. Sensing the outside world: TSLP regulates barrier immunity. Nat Immunol (2010) 11:289-93. doi:10.1038/ni.1852

10. Al-Shami A, Spolski R, Kelly J, Fry T, Schwartzberg PL, Pandey A, et al. A role for thymic stromal lymphopoietin in CD4(+) T cell development. J Exp Med (2004) 200:159-68. doi:10.1084/jem.20031975

11. Lei L, Zhang Y, Yao W, Kaplan MH, Zhou B. Thymic stromal lymphopoietin interferes with airway tolerance by suppressing the generation of antigen-specific regulatory T cells. J Immunol (2011) 186:2254-61. doi:10.4049/ jimmunol.1002503

12. Moret FM, Hack CE, Van Der Wurff-Jacobs KMG, Radstake TRDJ, Lafeber FPJG, van Roon JAG. Thymic stromal lymphopoietin, a novel proinflammatory mediator in rheumatoid arthritis that potently activates CD1c+ myeloid dendritic cells to attract and stimulate T cells. Arthritis Rheumatol (2014) 66:1176-84. doi:10.1002/art.38338

13. Mazzucchelli R, Durum SK. Interleukin-7 receptor expression: intelligent design. Nat Rev Immunol (2007) 7:144-54. doi:10.1038/nri2023

14. Puel A, Ziegler SF, Buckley RH, Leonard WJ. Defective IL7R expression in $\mathrm{T}(-) \mathrm{B}(+) \mathrm{NK}(+)$ severe combined immunodeficiency. Nat Genet (1998) 20:394-7. doi:10.1038/3877

15. Zenatti PP, Ribeiro D, Li W, Zuurbier L, Silva MC, Paganin M, et al. Oncogenic IL7R gain-of-function mutations in childhood T-cell acute lymphoblastic leukemia. Nat Genet (2011) 43:932-9. doi:10.1038/ng.924

16. Silva A, Laranjeira ABA, Martins LR, Cardoso BA, Demengeot J, Yunes JA, et al. IL-7 contributes to the progression of human T-cell acute lymphoblastic leukemias. Cancer Res (2011) 71:4780-9. doi:10.1158/0008-5472. CAN-10-3606

17. Teutsch S, Booth D. Identification of 11 novel and common single nucleotide polymorphisms in the interleukin-7 receptor- $\alpha$ gene and their associations with multiple sclerosis. Eur J Hum Genet (2003) 11:509-15. doi:10.1038/ sj.ejhg.5200994

18. Lundmark F, Duvefelt K, Iacobaeus E, Kockum I, Wallström E, Khademi $\mathrm{M}$, et al. Variation in interleukin 7 receptor alpha chain (IL7R) influences risk of multiple sclerosis. Nat Genet (2007) 39:1108-13. doi:10.1038/ ng2106

19. Heron M, Grutters JC, van Moorsel CHM, Ruven HJT, Huizinga TWJ, van der Helm-van Mil AHM, et al. Variation in IL7R predisposes to sarcoid inflammation. Genes Immun (2009) 10:647-53. doi:10.1038/gene.2009.55

20. Anderson CA, Boucher G, Lees CW, Franke A, D'Amato M, Taylor KD, et al. Corrigendum: meta-analysis identifies 29 additional ulcerative colitis risk loci, increasing the number of confirmed associations to 47. Nat Genet (2011) 43:246-52. doi:10.1038/ng0911-919b

21. Shamim Z, Ryder LP, Heilmann C, Madsen H, Lauersen H, Andersen PK, et al. Genetic polymorphisms in the genes encoding human interleukin-7 receptor-alpha: prognostic significance in allogeneic stem cell transplantation. Bone Marrow Transplant (2006) 37:485-91. doi:10.1038/sj.bmt.1705277

22. Shamim Z, Ryder LP, Christensen IJ, Toubert A, Norden J, Collin M, et al. Prognostic significance of interleukin-7 receptor- $\alpha$ gene polymorphisms in allogeneic stem-cell transplantation: a confirmatory study. Transplantation (2011) 91:731-6. doi:10.1097/TP.0b013e31820f08b2

23. Shamim Z, Spellman S, Haagenson M, Wang T, Lee SJ, Ryder LP, et al. Polymorphism in the interleukin-7 receptor-alpha and outcome after allogeneic hematopoietic cell transplantation with matched unrelated donor. Scand J Immunol (2013) 78:214-20. doi:10.1111/sji.12077

24. Gratwohl A, Carreras E. Principles of conditioning. In: Apperley J, Carreras E, Gluckman E, Masszi T, editors. The EBMT Handbook. (2012)

25. Enevold C, Oturai AB, Sørensen PS, Ryder LP, Koch-Henriksen N, Bendtzen K. Multiple sclerosis and polymorphisms of innate pattern recognition receptors TLR1-10, NOD1-2, DDX58, and IFIH1. J Neuroimmunol (2009) 212:125-31. doi:10.1016/j.jneuroim.2009.04.008

26. Sullivan K, Mannucci A, Kimpton C, Gill P. A rapid and quantitative DNA sex test: fluorescence-based PCR analysis of X-Y homologous gene amelogenin. Biotechniques (1993) 15:636-41.

27. Singh AK, Mcguirk JP. Allogeneic stem cell transplantation: a historical and scientific overview. Cancer Res (2016) 76:6445-52. doi:10.1158/0008-5472. CAN-16-1311

28. Im A, Hakim FT, Pavletic SZ. Novel targets in the treatment of chronic graftversus-host disease. Leukemia (2017) 31:543-54. doi:10.1038/leu.2016.367

29. Azarpira N, Dehghani M, Aghdaie MH, Darai M. Interleukin-7 receptor-alpha gene polymorphisms in bone marrow transplant recipients. Mol Biol Rep (2010) 37:27-31. doi:10.1007/s11033-009-9488-4

30. Kielsen K, Shamim Z, Thiant S, Faucher S, Decker W, Christensen IJ, et al. Soluble Interleukin-7 receptor levels and risk of acute graft-versus-disease after allogeneic haematopoietic stem cell transplantation. Clin Immunol (2017). doi:10.1016/j.clim.2017.08.015

31. Mackall CL, Fleisher TA, Brown MR, Andrich MP, Chen CC, Feuerstein IM, et al. Age, thymopoiesis, and CD4+ T-lymphocyte regeneration after intensive chemotherapy. N Engl JMed (1995) 332:143-9. doi:10.1056/ NEJM199501193320303

32. Sauce D, Larsen M, Fastenackels S, Roux A, Gorochov G, Katlama C, et al. Lymphopenia-driven homeostatic regulation of naive $\mathrm{T}$ cells in elderly and thymectomized young adults. J Immunol (2012) 189:5541-8. doi:10.4049/ jimmunol.1201235

33. Krenger W, Blazar BR, Holländer GA. Thymic T-cell development in allogeneic stem cell transplantation. Blood (2011) 117:6768-76. doi:10.1182/ blood-2011-02-334623

34. Toubert A, Glauzy S, Douay C, Clave E. Thymus and immune reconstitution after allogeneic hematopoietic stem cell transplantation in humans: never say never again. Tissue Antigens (2012) 79:83-9. doi:10.1111/j.1399-0039.2011.01820.x

35. Williams KM, Hakim FT, Gress RE. T cell immune reconstitution following lymphodepletion. Semin Immunol (2007) 19:318-30. doi:10.1016/j. smim.2007.10.004

36. Chazen GD, Pereira GM, LeGros G, Gillis S, Shevach EM. Interleukin 7 is a T-cell growth factor. Proc Natl Acad Sci U S A (1989) 86:5923-7. doi:10.1073/ pnas.86.15.5923

37. Costello R, Brailly H, Mallet F, Mawas C, Olive D. Interleukin-7 is a potent co-stimulus of the adhesion pathway involving CD2 and CD28 molecules. Immunology (1993) 80:451-7.

38. Schluns KS, Kieper WC, Jameson SC, Lefrançois L. Interleukin-7 mediates the homeostasis of naïve and memory CD8 T cells in vivo. Nat Immunol (2000) 1:426-32. doi:10.1038/80868

39. Kielsen K, Jordan KK, Uhlving HH, Pontoppidan PL, Shamim Z, Ifversen M, et al. $\mathrm{T}$ cell reconstitution in allogeneic haematopoietic stem cell transplantation: prognostic significance of plasma interleukin-7. Scand J Immunol (2015) 81:72-80. doi:10.1111/sji.12244

40. Thiant S, Yakoub-Agha I, Magro L, Trauet J, Coiteux V, Jouet J-P, et al. Plasma levels of IL-7 and IL-15 in the first month after myeloablative BMT are predictive biomarkers of both acute GVHD and relapse. Bone Marrow Transplant (2010) 45:1546-52. doi:10.1038/bmt.2010.13

41. Dean RM, Fry T, Mackall C, Steinberg SM, Hakim F, Fowler D, et al. Association of serum interleukin-7 levels with the development of acute graft-versus-host disease. J Clin Oncol (2008) 26:5735-41. doi:10.1200/JCO.2008.17.1314

42. Rosenberg SA, Sportès C, Ahmadzadeh M, Fry TJ, Ngo LT, Schwarz SL, et al. IL-7 administration to humans leads to expansion of CD8+ and CD4+ cells but a relative decrease of CD4+ T-regulatory cells. J Immunother (2006) 29:313-9. doi:10.1097/01.cji.0000210386.55951.c2

43. Le Campion A, Pommier A, Delpoux A, Stouvenel L, Auffray C, Martin B, et al. IL-2 and IL-7 determine the homeostatic balance between the regulatory and conventional CD4+ T cell compartments during peripheral $\mathrm{T}$ cell reconstitution. J Immunol (2012) 189:3339-46. doi:10.4049/jimmunol.1103152

44. Heninger A-K, Theil A, Wilhelm C, Petzold C, Huebel N, Kretschmer K, et al. IL-7 abrogates suppressive activity of human CD4+CD25+FOXP3+ regulatory $\mathrm{T}$ cells and allows expansion of alloreactive and autoreactive $\mathrm{T}$ cells. J Immunol (2012) 189:5649-58. doi:10.4049/jimmunol.1201286

45. Lundström W, Fewkes NM, Mackall CL. IL-7 in human health and disease. Semin Immunol (2012) 24:218-24. doi:10.1016/j.smim.2012.02.005 
46. Jäger J, Schulze C, Rösner S, Martin R. IL7RA haplotype-associated alterations in cellular immune function and gene expression patterns in multiple sclerosis. Genes Immun (2013) 14:453-61. doi:10.1038/gene.2013.40

47. Gregory SG, Schmidt S, Seth P, Oksenberg JR, Hart J, Prokop A, et al. Interleukin 7 receptor alpha chain (IL7R) shows allelic and functional association with multiple sclerosis. Nat Genet (2007) 39:1083-91. doi:10.1038/ ng2103

48. Crawley AM, Faucher S, Angel JB. Soluble IL-7R alpha (sCD127) inhibits IL-7 activity and is increased in HIV infection. JImmunol (2010) 184:4679-87. doi:10.4049/jimmunol.0903758

49. Rajasuriar R, Booth D, Solomon A, Chua K, Spelman T, Gouillou M, et al. Biological determinants of immune reconstitution in HIV-infected patients receiving antiretroviral therapy: the role of interleukin 7 and interleukin 7 receptor $\alpha$ and microbial translocation. J Infect Dis (2010) 202:1254-64. doi:10.1086/656369

50. Hartling HJ, Ryder LP, Ullum H, Ødum N, Nielsen SD. Gene variation in IL-7 receptor (IL-7R) $\alpha$ affects IL-7R response in CD4 + T cells in HIV-infected individuals. Sci Rep (2017) 7:1-8. doi:10.1038/srep42036

51. Poiret T, Rane L, Remberger M, Omazic B, Gustafsson-Jernberg A, Vudattu NK, et al. Reduced plasma levels of soluble interleukin-7 receptor during graftversus-host disease (GVHD) in children and adults. BMC Immunol (2014) 15:25. doi:10.1186/1471-2172-15-25

52. Shamim Z, Müller K, Svejgaard A, Poulsen LK, Bodtger U, Ryder LP. Association between genetic polymorphisms in the human interleukin-7 receptor $\alpha$-chain and inhalation allergy. Int J Immunogenet (2007) 34:149-51. doi:10.1111/j.1744-313X.2007.00657.x

53. Todd JA, Walker NM, Cooper JD, Smyth DJ, Downes K, Plagnol V, et al. Robust associations of four new chromosome regions from genome-wide analyses of type 1 diabetes. Nat Genet (2007) 39:857-64. doi:10.1038/ng2068

54. Badot V, Luijten RKMAC, van Roon JA, Depresseux G, Aydin S, Van den Eynde BJ, et al. Serum soluble interleukin 7 receptor is strongly associated with lupus nephritis in patients with systemic lupus erythematosus. Ann Rheum Dis (2013) 72:453-6. doi:10.1136/annrheumdis-2012-202364
55. Kreft KL, Verbraak E, Wierenga-Wolf AF, van Meurs M, Oostra BA, Laman JD, et al. Decreased systemic IL-7 and soluble IL-7R $\alpha$ in multiple sclerosis patients. Genes Immun (2012) 13:587-92. doi:10.1038/gene.2012.34

56. Hartgring SAY, van Roon JAG, Wenting-van Wijk M, Jacobs KMG, Jahangier ZN, Willis CR, et al. Elevated expression of interleukin-7 receptor in inflamed joints mediates interleukin-7-induced immune activation in rheumatoid arthritis. Arthritis Rheum (2009) 60:2595-605. doi:10.1002/art.24754

57. Monti P, Brigatti C, Krasmann M, Ziegler AG, Bonifacio E. Concentration and activity of the soluble form of the Interleukin-7 receptor alpha in type I diabetes identifies an interplay between hyperglycemia and immune function. Diabetes (2013) 62:2500-8. doi:10.2337/db12-1726

58. Lundström W, Highfill S, Walsh STR, Beq S, Morse E, Kockum I, et al. Soluble IL7R $\alpha$ potentiates IL-7 bioactivity and promotes autoimmunity. Proc Natl Acad Sci U S A (2013) 110:E1761-70. doi:10.1073/ pnas. 1222303110

59. Milford TAM, Su RJ, Francis OL, Baez I, Martinez SR, Coats JS, et al. TSLP or IL-7 provide an IL-7R $\alpha$ signal that is critical for human B lymphopoiesis. Eur J Immunol (2016) 46:2155-61. doi:10.1002/eji.201646307

60. Socié G, Ritz J. Current issues in chronic graft-versus-host disease. Blood (2014) 124:374-84. doi:10.1182/blood-2014-01-514752

Conflict of Interest Statement: AP is affiliated with Merck A/S; however, the present work is unrelated to this affiliation. All other authors report no conflicts of interest. The authors alone are responsible for the content and writing of the paper.

Copyright $(2018$ Kielsen, Enevold, Heilmann, Sengeløv, Pedersen, Ryder and Müller This is an open-access article distributed under the terms of the Creative Commons Attribution License (CC BY). The use, distribution or reproduction in other forums is permitted, provided the original author(s) and the copyright owner are credited and that the original publication in this journal is cited, in accordance with accepted academic practice. No use, distribution or reproduction is permitted which does not comply with these terms. 